\title{
Synthesis and characterization of nanoboron powders prepared with mechanochemical reaction between $\mathrm{B}_{2} \mathrm{O}_{3}$ and Mg powders
}

\author{
ALI SEIFOLAZADEH and SAMANEH MOHAMMADI* \\ Malek-Ashtar University of Technology, School of Chemistry and Chemical Engineering, Tehran, P.O. Box 15875-1774, \\ Islamic Republic of Iran
}

MS received 21 July 2015; accepted 21 September 2015

\begin{abstract}
Amorphous boron powders with small particle size, narrow size distribution and high purity are very important in the high-tech fields. Mechanochemical synthesis was used to prepare amorphous boron nanoparticles. Synthesis process stage was carried out using stoichiometric amounts of $\mathrm{B}_{2} \mathrm{O}_{3}$ and $\mathrm{Mg}$ powders $(6.7 \mathrm{~g})$. Milling was carried out under argon atmosphere in the high-energy planetary ball mill with a ball-to-powder weight ratio $(32: 1)$ for $10 \mathrm{~h}$. The vial rotation speed was about $440 \mathrm{rpm}$. Milled products were leached by $28 \%$ hydrochloric acid (only one) to remove impurities. Boron powders were obtained after centrifuging, decanting, washing and drying operations. Sample was characterized by inductively coupled plasma (ICP), energy-dispersive spectroscopy, X-ray diffraction, scanning electron microscopy (SEM) and transmission electron microscopy (TEM). The ICP results showed that boron powders with purity about $91 \mathrm{wt} \%$ can be prepared in the planetary ball mill. Also, the leached powders had an amorphous structure. According to the SEM observation, average particle size of boron powders was smaller than $32 \mathrm{~nm}$ and the yield of synthesized nanoboron was more than $74 \%$.
\end{abstract}

Keywords. Nanoparticle; boron; mechanochemical reaction; amorphous phase.

\section{Introduction}

Boron is one of the least understood elements that can be applied in semiconductor field. It releases the highest volumetric heat of combustion $\left(135.8 \mathrm{MJ}^{-1}\right)$. Also, it has the third highest gravimetric heat of combustion $\left(58.5 \mathrm{MJ} \mathrm{kg}^{-1}\right)$, after $\mathrm{H}_{2}$ and $\mathrm{Be}$. Boron has potential for using in the fuel or adding to fuel as the additive [1,2]. There are crystalline and amorphous structures for boron powders. The reactivity of boron powders depend on its form (crystalline structure and amorphous structure). Amorphous boron powder has a higher energy density than the fuels like magnesium, hydrocarbon and carbon. Also, it exhibits a high melting point (about $2300^{\circ} \mathrm{C}$ ), high hardness, suitable chemical inertness and thermal stability, low density $\left(2.3 \mathrm{~g} \mathrm{~cm}^{-3}\right)$, superior interesting electrical properties. These properties cause amorphous boron powders an attractive prospect for practical applications in several fields such as thermo-electric energy conversion, high energetic material, high-temperature devices and refractory materials $[3,4]$.

There are different methods for preparation of boron powders in micron and nano-size scales. Important methods include: (1) metallothermic method: reduction of boron compounds (such as boron oxide, halogenides and fluoroborates) by metals at high temperature $(\mathrm{Mg}$ is the suitable reducing agent), (2) reduction of boron halides with hydrogen, (3) thermal decomposition of boron compounds (such as boron halides and hydrides) and (4) electrolytic reduction

\footnotetext{
*Author for correspondence (S_Mohammadi_Chem_Eng@yahoo.com)
}

method: electrolysis of molten borates or fluoroborates [5,6]. Furthermore, boron nanopowders have been synthesized by arc decomposition of $\mathrm{B}_{2} \mathrm{H}_{6}$ reduction of $\mathrm{BCl}_{3}(\mathrm{~g})$ in an inductively coupled plasma (ICP) (about $50 \mathrm{~nm}$ ), solution reduction of $\mathrm{BBr}_{3}$ with sodium naphthalenide [7], gas phase pyrolysis of decaborane $(10-150 \mathrm{~nm})$ [8]. Also, ball milling process of coarse boron powders was used to prepare boron nanoparticles in a Spex-CertiPrep 8000M mixer mill (highenergy ball mill) using a tungsten carbide milling jar (about $50 \mathrm{~nm}$ ) [1,9]. From these methods, boron halids reduction method is very dangerous, containing the reaction between highly reactive gases $\left(\mathrm{H}_{2}\right.$ and $\left.\mathrm{BCl}_{3}\right)$, and the formation of a highly corrosive gas $(\mathrm{HCl})$ in high temperature [6].

The magnesiothermic reduction is a self-propagating high temperature synthesis (SHS), which is the way for preparation of various materials. In this method, reaction starts by external heating and continues with energy supplied by the reaction. Anyway, it is difficult to control the SHS reaction process because of the high exothermic effect in a few seconds. In this technique, final products have many types of impurities such as $\operatorname{Mg}_{x} \mathrm{~B}_{2} \mathrm{O}_{(x+1)}(x=2,3), \mathrm{B}_{x} \mathrm{O}, \mathrm{MgB}_{x}(x=$ $2,4,6$ ), and leached final powders have low purity about 88 $\mathrm{wt} \%$ and product has a large particle size (about $0.5-5 \mu \mathrm{m}$ ). This method needs to high-volume argon gas and high-cost equipments $[3,4]$.

In addition to the above methods, boron powders can be synthesized by mechanochemical reaction in high-energy ball mill [10-12]. Mechanical synthesis of the powder mixtures containing boron compounds (such as $\mathrm{B}_{2} \mathrm{O}_{3}$ or $\mathrm{H}_{3} \mathrm{BO}_{3}$ powders) and reducing agents (such as $\mathrm{Mg}$ or $\mathrm{Al}$ powders) is 
a new way to obtain boron powders. This process can be performed at room temperature [3].

For the first time, Darvishi and co-workers [10] prepared boron powders by mechanochemical synthesis in a SPEX 8000. After that, Ricceri and Matteazzi [11] and Agaogulliari et al [12] prepared boron powders in the SPEX ball mill by this method in the different conditions. These researchers used only SPEX ball mill (laboratory mill).

Nanostructured elements or compound can be prepared by variety techniques. One of the methods is high-energy ball milling powders or synthesis by ball milling [13]. In the method, welding, deformation of materials, fracture of initial powders and chemical reaction takes place at the interface of particles during milling in low temperature (without external heating). Therefore, solid-state reaction or solid-liquid reaction can be occurred in a milling device without external heating [14]. In the method, some reactions have been reported such as displacement reactions of the type

$$
\mathrm{MO}+\mathrm{R} \rightarrow \mathrm{M}+\mathrm{RO} .
$$

In this reaction, metal oxide (MO) is reacted by a more reactive metal ( $\mathrm{R}$, such as $\mathrm{Mg}, \mathrm{Al}$, etc.) to prepare pure metal (M) and these reactions are described by change in a large negative free energy (Gibbs free energy) and so, they are thermodynamically possible at room temperature. The occurrence of these reactions is restricted by kinetics investigations [15].

According to the milling conditions, the mechanical reaction can be carried out in two different kinetics ways: (1) a self-propagating reaction that can be initiated when the reaction enthalpy is sufficiently high (MSR process) and (2) a gradual transformation of the reactant. The first reaction requires a critical time for the ignition and combustion reaction. The MSR process has been shown that the mill temperature initially increases slowly with time. After a certain period of milling, the temperature increases abruptly, confirming that ignition has taken place. The time at which a rapid increase in temperature happens is ascribed to as the ignition time $\left(t_{\mathrm{ig}}\right)$. After this time the reaction occurs quickly. This temperature depends on the enthalpy change and microstructure factors of reactants (brittle, ductile, etc.) $[15,16]$. Mechanical synthesis kinetics can be depended on several agents such as the thermodynamic properties of the reaction, the mechanical properties of the reactants, and milling parameters such as the impact energy and frequency [17]. For determination of the reaction kinetics is usually used from adiabatic temperature. In the ball milling (MSR process), $T_{\text {ad }}$ more than $1800 \mathrm{~K}$ (sometimes $2000 \mathrm{~K}$ ) is necessary for a reaction to become self-sustaining, but the milling conditions can affect on the process kinetics [18,19].

The main goal of this paper is to introduce a low cost way for preparation of nanoboron powders with purity more than $90 \%$ in the planetary ball mill at room temperature. This process does not need to use gas phase materials as initial compounds. Therefore, this method is safer than other mentioned methods. To the best of our knowledge, the mechanochemical synthesis of boron nanopowders from $\mathrm{B}_{2} \mathrm{O}_{3}-\mathrm{Mg}$ system in a planetary ball mill has not previously been reported in the references. Boron powders were synthesized via a twostage process involving (a) mechanochemical reaction of an exothermic mixture consisting of boron trioxide $\left(\mathrm{B}_{2} \mathrm{O}_{3}\right)$ and magnesium ( $\mathrm{Mg}$ ), and (b) extraction of boron powders from the final milled product by leaching with hydrochloric acid 28 wt\% (only one) and washing. The novelty of this paper is that particle size of mechanically synthesized boron powders in a planetary ball mill is reported for the first time. Also, the reaction kinetics in this process was investigated by temperature measurements and X-ray diffraction (XRD) analyses. Moreover, some obtained results were compared with the results that have been reported for SHS process (magnesiothermic reduction).

\section{Materials and procedure}

\subsection{Materials and methods}

Raw materials contained boron oxide $\left(\mathrm{B}_{2} \mathrm{O}_{3}\right.$, purity: $99.99 \%$, United Arab, micron size about $300 \mu \mathrm{m}$ ) and magnesium (Mg, purity: 99.99\%, Merck, flake, particle size smaller than $1 \mathrm{~mm})$. In this experiment, $3.3 \mathrm{~g} \mathrm{~B}_{2} \mathrm{O}_{3}$ and $3.4 \mathrm{~g} \mathrm{Mg}$ were mixed with ball-to-powder weight ratio (BPR, 32 : 1). Initial materials containing stoichiometric amounts of reactants were prepared in agreement with the exothermic reaction

$$
\mathrm{B}_{2} \mathrm{O}_{3}+3 \mathrm{Mg} \rightarrow 2 \mathrm{~B}+3 \mathrm{MgO} \text {. }
$$

Milling container was hardened steel vial with a capacity of $250 \mathrm{~cm}^{3}$ and milling media was hardened steel balls ( 6 balls with diameter of $18 \mathrm{~mm}$ and a ball with diameter of $13 \mathrm{~mm}$ ). The container was filled with argon (purity: 99\%) to hinder oxidation of products and milled powders during the reaction (under 3 bar of argon gas). The mixed powders were milled in a planetary ball-mill (Model: NARYA-MPM $2 * 250$, Amin Industrial Manufacturing Co.) with a rotation speed of vial $440 \mathrm{rpm}$. Milling was carried out for $10 \mathrm{~h}$ (working time: $50 \mathrm{~min}$, resting time: $10 \mathrm{~min}$ ). Also, this process was performed in a vial without reactants for determining external temperature of vial during ball milling.

Milled powders were leached by $\mathrm{HCl}$ solution (Merck, $28 \%$ ) at a temperature between $60-70^{\circ} \mathrm{C}$ by a heater-magnetic stirrer to remove other solid by-products such as $\mathrm{MgO}$ and other impurities such as $\mathrm{Fe}$ or $\mathrm{Fe}_{2} \mathrm{O}_{3}$ or $\mathrm{Mg}, \mathrm{B}, \mathrm{O}$ components. Solid/leachant weight ratio and acid leaching time were chosen as $1 \mathrm{~g} / 30 \mathrm{ml}$ and $4 \mathrm{~h}$, respectively. Final product was prepared after several centrifuging, decanting, washing (deionized water, $4 \mathrm{~h}, 100^{\circ} \mathrm{C}$ ). Drying treatment was carried out in a vacuum oven at $50^{\circ} \mathrm{C}$ for $12 \mathrm{~h}$.

\subsection{Characterization of powders}

The thermochemical behaviour of the reaction in SHS mode (for initial reactants), ball-milled mixture powders after $2 \mathrm{~h}$ and purified powders were characterized by differential scanning calorimetry (DSC) analyses. A Mettler Toledo system 
was employed for DSC studies at the temperature range of $25-1400^{\circ} \mathrm{C}$ in the $\arg$ on atmosphere. The heating rates were $30^{\circ} \mathrm{C} \mathrm{m^{-1 }}$. External temperature of the vial was measured using a noncontact infrared thermometer in order to investigate the reaction kinetics. The structures of milled and leached powders were determined by XRD using $\mathrm{Cu} \mathrm{K} \alpha$ radiation (Philips Analytical X-Ray B.V.). ICP analysis was used for determination of $\mathrm{B}, \mathrm{Mg}$ and $\mathrm{Fe}$ in the final leached product by ICP-AES system (model: Perkin Elmer 53000 V). Also, energy-dispersive spectroscopy (EDS) investigation of the purified powders was performed using Philips XL30 ESEM. Particle size was determined by scanning electron microscopy (SEM) analysis (KYKY China, model: EM3200) and transmission electron microscopy (TEM) analysis (Philips, model: CM120).

\section{Results and discussion}

\section{$3.1 \mathrm{~B}_{2} \mathrm{O}_{3}-\mathrm{Mg}$ reaction process}

Figure 1 shows DSC result of $\mathrm{B}_{2} \mathrm{O}_{3}-\mathrm{Mg}$ reaction (in stoichiometry amounts).

From figure 1, it can be seen that there is a sharp exothermic peaks at $1033^{\circ} \mathrm{C}$. After melting $\mathrm{B}_{2} \mathrm{O}_{3}$ and $\mathrm{Mg}\left(\right.$ at $\left.650^{\circ} \mathrm{C}\right)$,

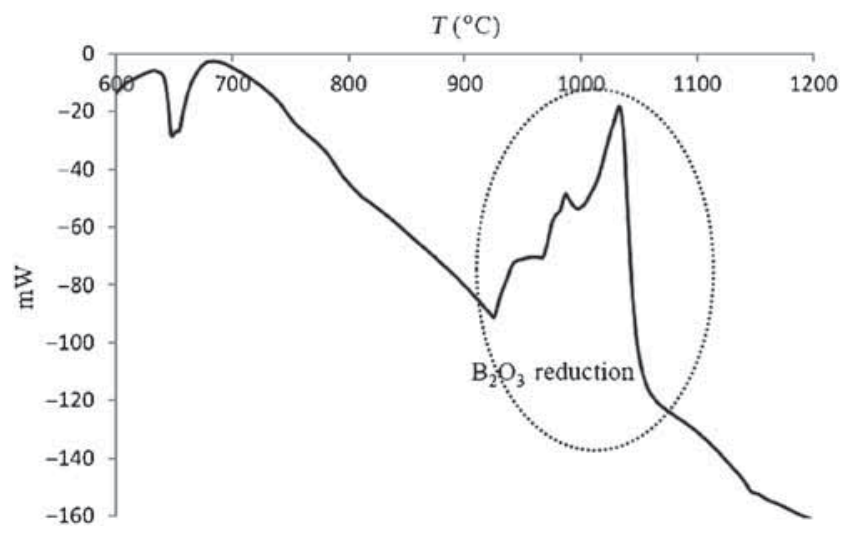

Figure 1. DSC pattern of $\mathrm{B}_{2} \mathrm{O}_{3}-\mathrm{Mg}$ reaction system.

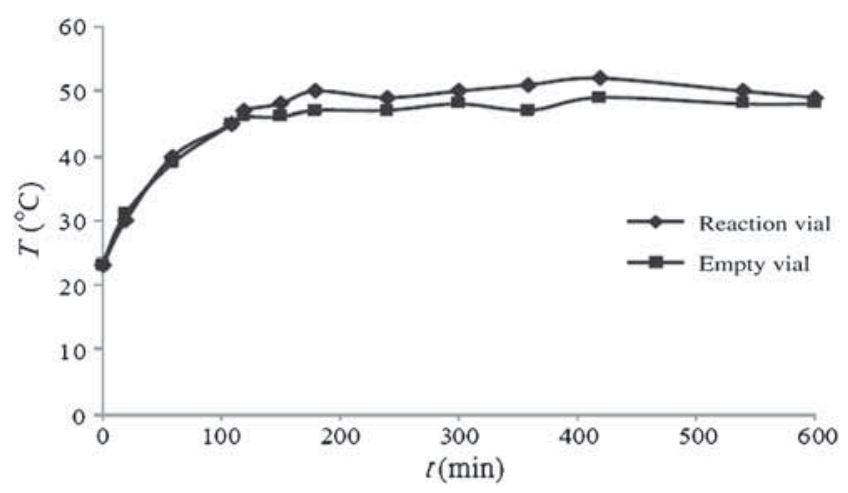

Figure 2. External temperature of vials as a function of milling time. at the temperature of about $980^{\circ} \mathrm{C}$, very small exothermic peak can be seen; the reason is that the melting of metal $\mathrm{Mg}$ increases the slow initial exothermic reaction. Finally, a sharp exothermic peak appeared at $1033^{\circ} \mathrm{C}$, implying that chemical reaction performed (in the liquid phase).

According to figure 1, this reaction can be performed in a SHS mode under initial heating by metallothermic reaction.

In some references, the reaction between $\mathrm{B}_{2} \mathrm{O}_{3}$ and $\mathrm{Mg}$ was introduced as a thermite reaction and it has enthalpy of about $-550.4 \mathrm{~kJ} \mathrm{~mol}^{-1}$. Also, it has a negative Gibbs free energy and $T_{\mathrm{ad}}$ for the reaction is $2460 \mathrm{~K}$ [20]. Therefore, the reaction can be performed as a MSR mode in the ball mill without external heating.

\subsection{Investigation of the reaction kinetics in the synthesis process}

Figure 2 shows the external temperature of vials for reaction vial (reactor) and empty vial under the employed experimental conditions.

From figure 2, until $2 \mathrm{~h}$ after milling, change in temperatures were the same and only reduction in particle size, defect density and particle refinement were happened, but with continuing the milling process, temperature of the reactor was more than another. It can be understood that after $2 \mathrm{~h}$ milling the reaction was initiated to form a gradual transformation or $t_{\text {ig }}$ decreased a lot and reaction was accrued in a MSR process but it cannot be detected. After about $8 \mathrm{~h}$ milling, the reaction completed (temperature was constant after $8 \mathrm{~h}$ ).

The above result is a complicated phenomenon. In addition to thermodynamic properties of reaction (such as enthalpy and Gibbs free energy) other parameters such as characteristics of reactants and milling conditions have the important effects on the milling process.

Mingliang and co-workers [21] worked on the important parameters that can cause a combustion reaction in a ball mill (MSR). They reported some results. For example, they claimed that the highly exothermic nature of a reaction that determines by adiabatic temperature or heat of reaction is not the most important factor for beginning a reaction in the MSR conditions, but it is a prior condition, whether or not MSR happens. They reported that the progress way of a reaction relies on the change in the reaction kinetics during milling. The mechanical characteristics, property of initial materials and the type of atomic bond of reactants have an important role in MSR process.

\subsection{Characterization of powders during the process}

Figure 3 shows the XRD patterns of initial reactants, milled powders in 2, 4, and $10 \mathrm{~h}$ and leached powders.

From figure 3 can be seen after $2 \mathrm{~h}$ milling, the reaction cannot be performed. But after $4 \mathrm{~h}, \mathrm{MgO}$ as a by-product produced and little $\mathrm{Mg}$ powders existed. Finally, after $10 \mathrm{~h}$, all of the initial reactants were consumed. From the XRD 
results and temperature measurements, it can be found that the reaction was performed in gradual mode and very low temperature in comparison with the SHS method.

Mechanochemical process has an important role in the reduction of reaction temperature and this point has effect on the reaction kinetics. Figure 4 shows DSC pattern of milled powders after $2 \mathrm{~h}$ milling.

As can be seen from figure 4 , the reaction temperature peak decreased to $742^{\circ} \mathrm{C}$. Decreasing the reaction temperature because of reduction in particle size, change in structure of initial materials and diffusion phenomenon have very important role in the reaction kinetics. Also, it can be found that safety can be increased with ball milling method.

In figure 3, crystalline boron phases (hexagonal, cubic and rhombohedral) cannot be detected in XRD pattern of leached boron (d). Also, there were not distinct crystalline impurity phases such as $\mathrm{Mg}_{3}\left(\mathrm{BO}_{3}\right)_{2}, \mathrm{~B}_{2} \mathrm{MgO}_{4}, \mathrm{Mg}_{2} \mathrm{~B}_{2} \mathrm{O}_{5}$, $\mathrm{MgB}_{6}, \mathrm{MgB}_{2}, \mathrm{MgB}_{12}, \mathrm{~B}_{2} \mathrm{O}_{3}, \mathrm{MgO}, \mathrm{Fe}_{2} \mathrm{O}_{3}$ in this pattern. In addition, no considerable peaks of other impurities, such as $\mathrm{MgB}_{x}$ and $\mathrm{B}_{x} \mathrm{O}$ are detected in the pattern. Therefore, it can be said that the final product does not have a distinct crystalline structure and boron powders under the experimental conditions have the amorphous phase.

In the ball milling process, various factors influence on the phase structure of final products. For example, the speed of balls and mill, the size and weight of balls, temperature, milling time and other variables can affect on the final structure of materials [15].

The influence of process variables on the amorphization behaviour has been reported in some systems [15]. For example: in the Ni-Zr system, amorphous phase did not produced at a BPR: 3 but at BPR: 5 (higher intensity), amorphous structure was produced (because of insufficient energy at low intensities). In this reference, the result showed that longer milling time cause to amorphization of powders [22]. In the Al-Ta system, it was reported that a fully amorphous phase was produced only at a BPR of $36: 1$ or $108: 1$ and in the BPR of $12: 1$ a crystalline phase was achieved. Also, at a BPR of $324: 1$, a mixture of a crystalline and amorphous phases was obtained [23]. In the another study, it has been shown that an amorphous structure was not obtained in ball milling with large diameter balls [24].

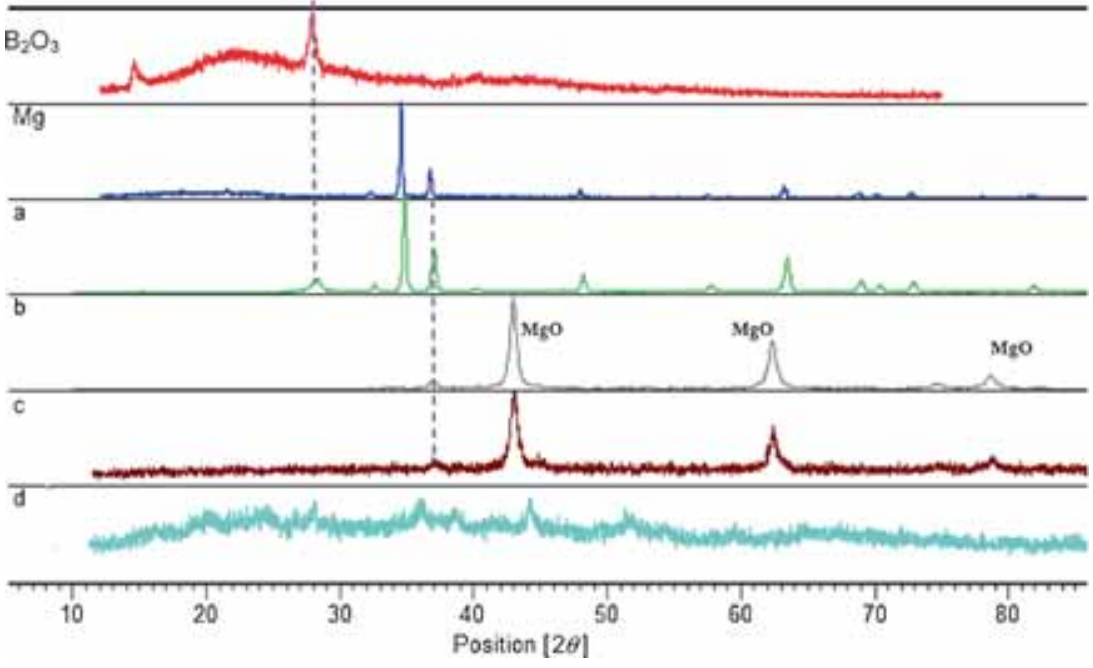

Figure 3. XRD patterns of reactants $\left(\mathrm{B}_{2} \mathrm{O}_{3}\right.$ and $\mathrm{Mg}$ ), and milled powders after (a) 2 h, (b) 4 h, (c) $10 \mathrm{~h}$ (before leaching) and (d) final powders (after leaching and washing).

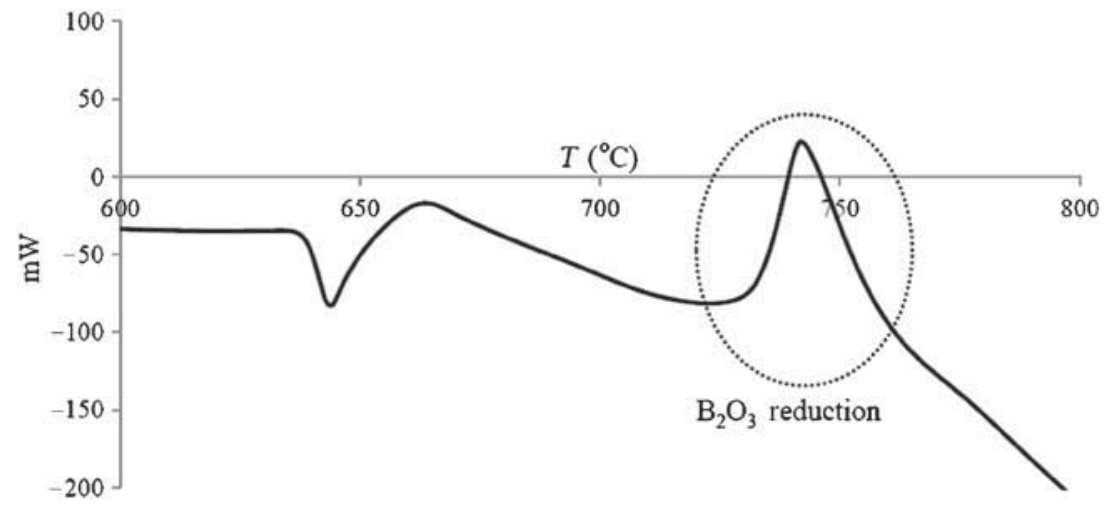

Figure 4. DSC pattern of $\mathrm{B}_{2} \mathrm{O}_{3}-3 \mathrm{Mg}$ reaction system after $2 \mathrm{~h}$ milling. 


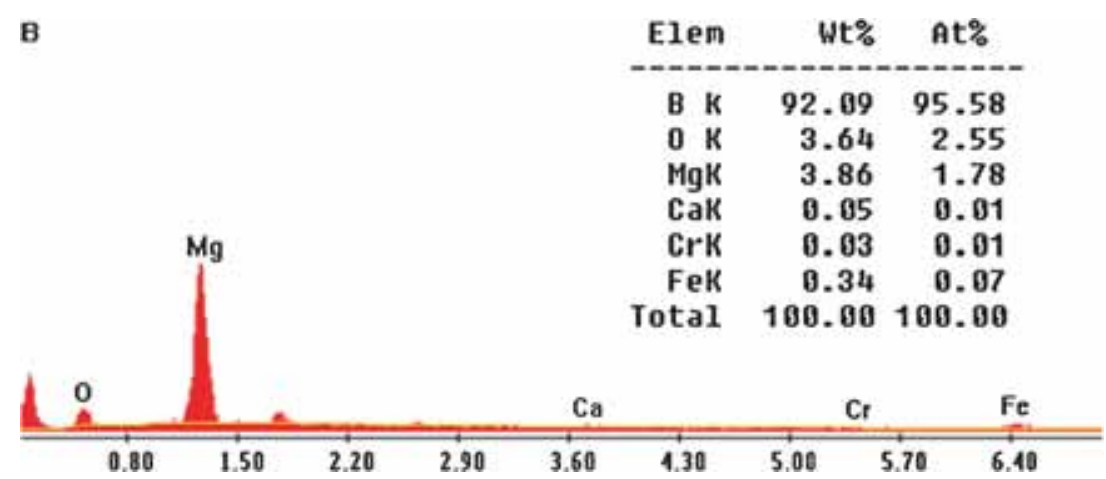

Figure 5. EDS pattern of synthesized boron powders in planetary ball mill.

Therefore, the important investigated variables are milling intensity (rotation speed of vial, BPR) and milling temperature. Augmented milling energy (obtained by a higher $\mathrm{BPR}$, high rotation speed, etc.) is expected to produce more strain and intensify the defect concentration in the powders and thus cause to easier amorphization. In addition, higher milling energy present more heat and higher temperature and this affect on the crystallization of the amorphous phases. Thus, a balance between the effects of the factors can be determined the nature of the final product phases [15].

In this work, the rotation speed and BPR are relatively high. Also, there was heat transfer from vial to environment (hardened steel vial and ball). Also, ball milling caused to reduction of reaction temperature. Therefore, it can be said that there is a balance between the factors and under the experimental conditions amorphous boron powders can be prepared. Moreover, the structure of initial powders affects on the final phase of product. Initial $\mathrm{B}_{2} \mathrm{O}_{3}$ powders had a mixture of crystalline and amorphous phases. After $2 \mathrm{~h}$ milling, the phase of $\mathrm{B}_{2} \mathrm{O}_{3}$ change to amorphous and amorphous boron structure can be related to this point. Also, it can be seen from the XRD patterns $b$ and $c$, with increasing the milling time, the structure of the milled powders becomes amorphous significantly.

\subsection{Chemical composition of leached powders}

In the leaching process, reaction (3) can be performed and by-products can be removed from milled powders

$$
\mathrm{MgO}+2 \mathrm{HCl} \rightarrow \mathrm{MgCl}_{2}+\mathrm{H}_{2} \mathrm{O} .
$$

$\mathrm{MgCl}_{2}$ is dissolved in water and removed after washing. Also, impurities such as $\mathrm{Fe}$ or $\mathrm{Fe}_{2} \mathrm{O}_{3}$ react with $\mathrm{HCl}$ and remove by washing. ICP analysis showed about $91 \mathrm{wt} \% \mathrm{~B}$, $5.2 \mathrm{wt} \% \mathrm{Mg}$ and $0.9 \mathrm{wt} \% \mathrm{Fe}$ in the final product. Also, figure 5 shows the weight $\%$ of elements in the leached powders.

Further results revealed that after twice acid leaching and washing, purity of final powders was improved to $92.7 \mathrm{wt} \%$ boron, $4.5 \mathrm{wt} \% \mathrm{Mg}$ and $\mathrm{Fe}$ can be removed by two times acid leaching completely (by ICP test). Also, more than twice purification steps cannot be affected on the purity of final products.

As can be seen from figure 5, in addition to B, other elements such as $\mathrm{O}$ and $\mathrm{Mg}$ exist in the purified powders. This result is related to this point that reaction did not completely perform in the reaction way and some by-products such as $\mathrm{Mg}_{2} \mathrm{~B}_{2} \mathrm{O}_{5}, \mathrm{Mg}_{3}\left(\mathrm{BO}_{3}\right)_{2}, \mathrm{~B}_{2} \mathrm{MgO}_{4}$ can be formed depending on the reaction conditions. Also, there is Fe element in this test that the impurity released from the milling media because of impact and shear between balls-powders, ball-powder-vial. It can be assumed that the presence of iron powders from milling media affects on the reaction kinetics such as PCA or inert salt and caused reaction occur in the gradual mode. According to the results, most of the impurities were removed by leaching process.

Finally, $0.73 \mathrm{~g}$ brown boron powders were collected. Therefore, the yield of boron production with $91 \%$ purity was more than $74 \%$. Compared with the SHS method, obtaining boron powders with the high purity is the important advantage for the method.

In addition to the above results, other samples with $\mathrm{B} / \mathrm{P}$ weight ratio: 10 (2 ball with diameter $18 \mathrm{~mm}$ ) and 20 ( 4 ball with diameter $18 \mathrm{~mm}$ ) under the employed experimental conditions were tested. The final results showed that boron powders cannot be prepared in these $\mathrm{B} / \mathrm{P}$ weight ratios and only reduction in particle size and diffusion were occurred.

Moreover, in the experimental conditions, a sample with $1.83 \mathrm{~g}$ total initial powders under BPR 30 (4 ball with diameter $13 \mathrm{~mm}$ ) was tested and result revealed that boron powder cannot be synthesized in these conditions. This result can be related to this point that produced energy in the milling process was not enough for performing the reaction.

Table 1. Chemical elements in boron powders obtained by EDS analysis (reported by Dou and co-workers [25]).

\begin{tabular}{lccl}
\hline Samples (in stoichiometric amounts) & $\mathrm{B} \%$ & $\mathrm{Mg} \%$ & $\mathrm{Fe} \%$ \\
\hline 1 (SHS method) & 85.03 & 13.3 & 0.07 \\
2 (ball milling [15 min, 300 rpm] + SHS) & 88.71 & 9.86 & 0.05 \\
3 (ball milling [20 min, 30 rpm] + SHS) & 92.86 & 6.47 & 0.3 \\
\hline
\end{tabular}




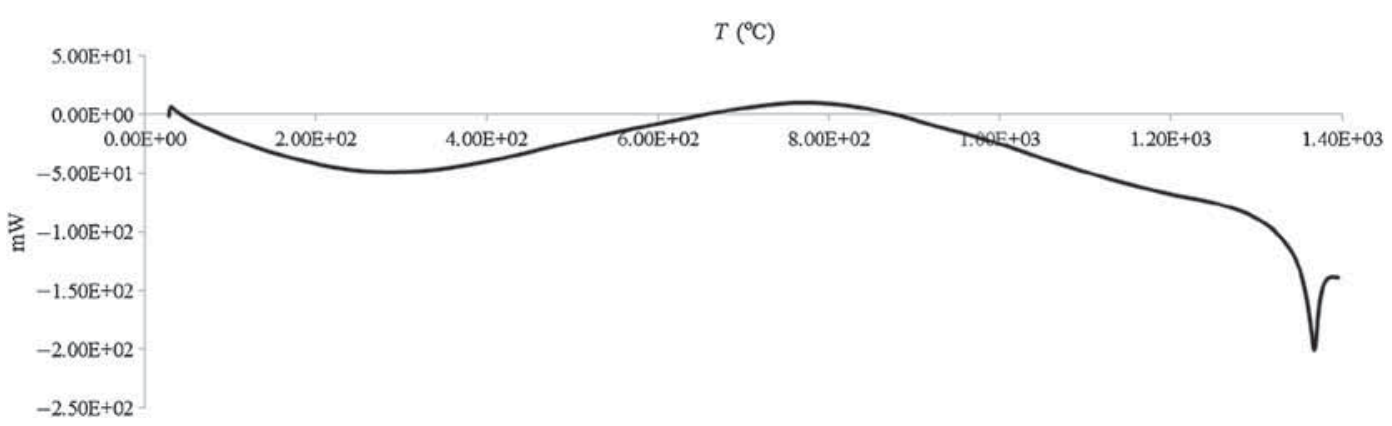

Figure 6. DSC pattern of purified boron powders.

Therefore, it can be found that many factors can be affected on the milling process and selection of the suitable preparative conditions has very important role in the mechanochemical synthesis method.

Dou and co-workers [25] published a paper about preparation of amorphous boron nanopowders. They reported composition of elements in boron powders that were prepared by the SHS method and ball milling-combustion synthesis method. Some results are summarized in table 1 .

As can be seen from table 1, high purity boron powder was obtained for sample 2, 3 in SHS + ball milling method. These results are similar to our results but mechanochemical reaction is a safer and cheaper (low temperature, consuming little argon component) than the SHS method. Moreover, content of $\mathrm{Mg}$ in the final product in the mechanical method is less than SHS method. In the high-energy ball milling, the mixed degree among the reactants can enhance and the reactant reactivity can improve to strengthen the reaction degree.

The reported results are revealed that $\mathrm{Mg}$ is an important impurity in the industrial amorphous boron powders such as SB86 (86\% B) and SB90 (90\%) [26,27]. In the metallothermic method, synthesizing boron powders with purity about $100 \%$ cannot be possible because other reactions can be performed (such as reactions of 4-6) with this reactants [28-30].

$$
\begin{aligned}
& 3 \mathrm{MgO}+\mathrm{B}_{2} \mathrm{O}_{3} \rightarrow \mathrm{Mg}_{3} \mathrm{~B}_{2} \mathrm{O}_{6}, \\
& \mathrm{~B}_{2} \mathrm{O}_{3}+4 \mathrm{Mg} \rightarrow \mathrm{MgB}_{2}+3 \mathrm{MgO}, \\
& 2 \mathrm{MgO}+\mathrm{B}_{2} \mathrm{O}_{3} \rightarrow \mathrm{Mg}_{2} \mathrm{~B}_{2} \mathrm{O}_{5} .
\end{aligned}
$$

Therefore, using initial materials in the reaction stoichiometry can be affected on the component of final powders.

After purification steps, DSC test was performed for final powders. Figure 6 shows the result of thermal analysis for purified boron powders.

Impurities such as $\mathrm{MgB}_{2}$ (melting point (decomposition): $\left.800^{\circ} \mathrm{C}\right)$ [31], $\mathrm{MgB}_{6}\left(1100^{\circ} \mathrm{C}\right)$ [31], $\mathrm{MgB}_{12}\left(1300^{\circ} \mathrm{C}\right)$ [31], $\mathrm{Mg}_{2} \mathrm{~B}_{2} \mathrm{O}_{5}\left(1360^{\circ} \mathrm{C}\right)$ [31], etc. can be existed in the purified powders.

As can be seen from figure 6, an endothermic peak in the $1366^{\circ} \mathrm{C}$ exists. It can be related to melting point of $\mathrm{Mg}_{2} \mathrm{~B}_{2} \mathrm{O}_{5}$.

\subsection{Morphology and particle size}

Figure 7 shows particle size of the leached boron powders by SEM analysis.

In figure 7 , the calculations were exhibited the average particle size after purification steps smaller than $32 \mathrm{~nm}$. It reveals that the powder does not have recognizable lattice fringes due to the amorphous character of powders.

Figure 8 also shows the size of boron nanopowder is ultrafine and smaller than $25 \mathrm{~nm}$.

Dou and co-workers [25] reported the size of boron powders that were synthesized by the SHS method. In this paper, the initial materials were contained $\mathrm{B}_{2} \mathrm{O}_{3}$ and $\mathrm{Mg}$ powders $(1: 3)$ and they were mixed in ordinary tank mixing for $3 \mathrm{~h}$ and then were placed in the reactor to ignite and the combustion synthesis reaction to synthesize products. They reported that structure of boron powders was rod-like crystals and particle size were in micron scale (length of about $1 \mu \mathrm{m}$ and the diameter of 100-200 nm). Therefore, the ball milling method has an important role in preparation of nanoboron powders in comparison with the SHS method.

Amorphous boron particles with small size, narrow size distribution and high purity are very significant in the hightech fields [32]. Therefore, this method and its scale up

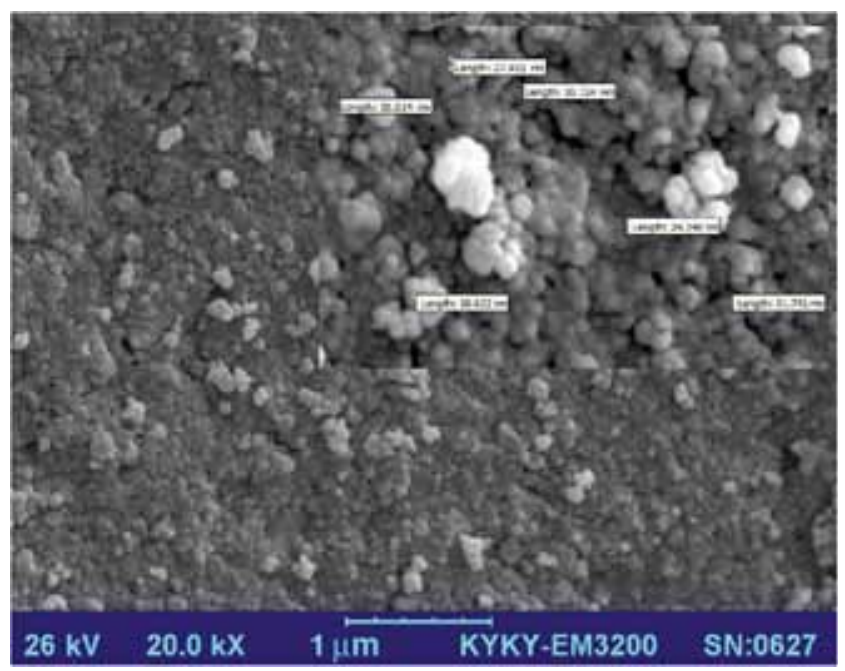

Figure 7. SEM micrograph of the boron nanoparticles. 


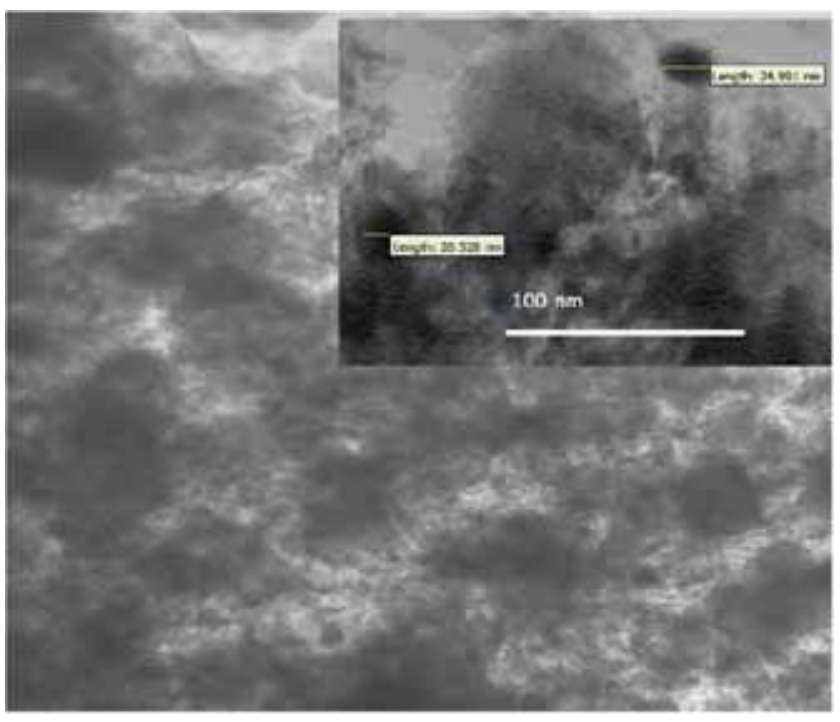

Figure 8. TEM micrograph of the boron nanoparticles.

are very important for many industries such as metallurgy, aerospace industry, etc.

A method to improve ignition and combustion of boron powders is to reduce the particle size to the nano-scale. Size reduction can provide large surface area and it may result in easy ignition of amorphous boron powders. The known ways to achieving boron nanoparticles (except of mechanochemical route) are few and most of them use the gas-phase compounds that there are some toxic and flammable gases [2].

Existence of agglomeration in boron nanopowders was observed in some reports [25,30,33]. Using argon atmosphere during storage of powders can be helped to reduced agglomeration powders.

\section{Conclusions}

In summary, nano-sized boron powders were prepared with exothermic reaction in the high energy planetary ball mill at room temperature. After only one acid leaching and washing process, final powders was obtained with purity about 91 wt $\% \mathrm{~B}$ and $5.2 \% \mathrm{Mg}$ by ICP test. Furthermore, in according to SEM analysis, the final product had a particle size in nanoscale range (average particle size about smaller than 32 $\mathrm{nm}$ ). The XRD analysis showed that the final product had an amorphous structure. Also, the yield of reaction was considerable (about 74\%). Therefore, mechanochemical process for synthesis of amorphous boron nanoparticles is the low cost method and safer than SHS process.

\section{Acknowledgements}

We thank the financial support from Malek-Ashtar University of Technology. SM thanks and appreciations also go to Eng. Eghdamtalab, Eng. Zarei and Eng. Kardan Halvaei in developing the project.

\section{References}

[1] Devener B V, Perez J P L, Jankovich J and Anderson S L 2009 J. Energy Fuels 36111

[2] Yoo B U, Nersisyan H H, Ryu H Y, Lee J S and Lee J H 2014 Combust. Flame 163222

[3] Neelameggham R 2012 J. Manuf. Sci. Prod. 12155

[4] Wang J, Gu Y, Li Z, Wang W and Fu Z 2013 Mater. Res. Bull. 482018

[5] Tavadze G F and Shteinberg A S 2013 Production of advanced materials by methods of self-propagating high temperature synthesis (Berlin, Heidelberg: Springer)

[6] Vignolo M, Romano G, Martinelli A, Bernini C and Siri A 2012 IEEE Trans. Appl. Supercond. 226200606

[7] Shin W G, Calder S, Ugurlu O and Girshick S L 2011 J. Nanopart. Res. 137187

[8] Bellott B J, Noh W, Nuzzo R G and Girolami G S 2009 J. Chem. Commun. 223214

[9] Devener B V, Perez J P L and Anderson S L 2009 Mater. Res. 243462

[10] Darvishi A H, Sabin B, Rene D and Julie J 2003 Process for the production of elemental boron by solid state reaction, World Intellectual Property Organization Patent, International publication number WO 03/051773

[11] Ricceri R and Matteazzi P 2003 Powder Metall. 3948

[12] Agaogulliari D, Balci O and Duman I 2010 Mechanism \& effects of various reducing agents on the fabrication of elemental boron. In: 19th international conference on metallurgy and materials, Roznov Pod Radhostem, Czech Republic, p 748-752

[13] Fan G J, Song X P, Quan M X and Hu Z Q 1996 Scr. Mater. 351065

[14] Ohara S, Sato K, Tan Z, Shimoda H, Ueda M and Fukui T 2010 J. Alloy Compd. 504 L17

[15] Suryarayana C 2001 Prog. Mater. Sci. 461

[16] Ciurowa K W and Gamrat K 2007 Mater. Sci-Poland 25219

[17] Mccormic R 2015 Mechanical alloying and mechanically induced chemical reactions. In: Handbook on the physics and chemistry of Rare Earths (eds) Jean-Claude Bünzli and Vitalij K Pecharsky (Elsevier) vol 48 p 2-379

[18] Takacs L 2002 Prog. Mater. Sci. 47355

[19] Moore J J and Feng H J 1995 Prog. Mater. Sci. 39275

[20] Sundaram V, Logan K V and Speyer R F 1997 J. Mater Res. 122657

[21] Mingliang M, Xinkuan L, Shengqi X, Donglang C and Jing'en Z 2001 J. Mater. Process. Technol. 116124

[22] Eckert J, Schultz L, Hellstern E and Urban K 1988 J. Appl. Phys. 643224

[23] El-Eskandarany M S, Aoki K, Itoh H and Suzuki K $1991 \mathrm{~J}$. Less Common Met. 169235

[24] Guo W, Iasonna A, Magini M, Martelli S and Padella F 1994 J. Mater. Sci. 292436

[25] Dou Z H, Zhang T, Shi G Y, Peng C, Wen M and He J C 2014 J. Trans. Nonferrous Met. Soc. China 241446 
[26] SB Boron 86 www.sbboron.com/pdf/SBBoron86specsheet.pdf

[27] SB Boron 90 www.sbboron.com/pdf/SBBoron90specsheet.pdf

[28] Weimin W, Zhengyi F, Hao W and Runzhang Y $2002 \mathrm{~J}$. Mater. Proc. Technol. 128162

[29] Yazici S and Derin B 2011 Int. J. Refractory Met. Hard Mater. 2990
[30] Nersisyan H H, Joo S H, Yoo B U, Cho Y H et al 2015 Combust. Flame 1623316

[31] Perry D L 2011 Handbook of inorganic compounds (CRC Press) 2nd ed.

[32] Zhou J and Bai P 2015 Asia-pacific J. Chem. Eng. 10325

[33] Gan Y, Lim Y S and Qiao L 2012 Combust. Flame 1591732 